\title{
Pituitary Gland Blastoma
}

National Cancer Institute

\section{Source}

National Cancer Institute. Pituitary Gland Blastoma. NCI Thesaurus. Code C155304.

A rare developmental early childhood neoplasm, arising within the fetal anterior pituitary.

It is associated with DICER1 mutations. Patients present with features of Cushing

disease, with elevated blood ACTH levels and hypercortisolism. Ophthalmoplegia is a

frequent symptom. The overall prognosis is poor. (WHO 2017) 